\title{
ACCESSORY HEADS OF FOREARM FLEXORS AND FLEXOR CARPI RADIALIS BREVIS: A CADAVERIC STUDY WITH CLINICALSIGNIFICANCE
}

\author{
Pushpa Burute ${ }^{* 1}$, P. Vatsalaswamy ${ }^{2}$. \\ ${ }^{{ }_{1}}$ Associate Professor, Department of Anatomy, BKL Walawalkar Rural Medical College, Sawarde, \\ Dist- Ratnagiri, Maharashtra, India. \\ ${ }^{2}$ Director Academics, Dr. D.Y. Patil Medical College \& Research centre, Dr. D. Y. Patil Vidyapeeth \\ Pune, Maharashtra, India.
}

\section{ABSTRACT}

Introduction: Muscular variations in the form of accessory muscles are common and observed during cadaveric dissections, surgeries or investigative radiological procedures. Knowledge of such variations in upper limb is useful for hand surgeons and neurosurgeons.

Materials and Methods: Total 156 (80 of right side and 76 of left side) upper limbs of unknown sex were dissected for presence of accessory muscles in the flexor compartment of the forearm. Observed accessory bellies and anatomical variant muscles were studied for its origin and insertion, size and shape and its important relations.

Observations: Accessory head for the flexor pollicis longus (ahFPL) was the most common variation found in 56 (36\%) limbs. Accessory head for the flexor digitorum profundus (ahFDP) was observed in five (3.2\%) limbs, and accessory head for the flexor digitorum superficialis (ahFDS) in two limbs $(1.2 \%$,$) . Two accessory bellies$ in the same hand with common or separate origin were found in 5 limbs (3.2\%). An anatomical variant flexor carpi radialis brevis (FCRB), which is not very common, was found in one limb.

Conclusion: Accessory bellies of the muscles in the forearm are known for compression neuropathies like anterior interosseous nerve syndrome (AINS). Available accessory muscles like FCRB could be used for tendon transfers in patients with arthritis of thumb. Awareness of such variations helps in diagnosis of neuropathies, to avoid complications during surgeries and most importantly accessory muscles could be used for tendon graft/ transfer to to transform disability into functional hands.

KEY WORDS: Forearm flexors, accessory muscles, Gantzer's muscle, Flexor carpi radialis brevis (FCRB), Double bellies.

Address for Correspondence: Dr. Pushpa Burute, Associate Professor, Department of Anatomy, BKL Walawalkar Rural Medical College, Sawarde, Dist- Ratnagiri, Maharashtra, India 415606 E-Mail: pushpaburute60@gmail.com

\begin{tabular}{|c|c|c|}
\hline \multicolumn{3}{|c|}{ Access this Article online } \\
\hline \multirow{3}{*}{$\begin{array}{l}\text { Quick Response code } \\
\text { DOI: } 10.16965 / \text { ijar.2017.145 }\end{array}$} & \multicolumn{2}{|c|}{$\begin{array}{l}\text { Web site: International Journal of Anatomy and Research } \\
\qquad \begin{array}{l}\text { ISSN 2321-4287 } \\
\text { www.ijmhr.org/ijar.htm }\end{array}\end{array}$} \\
\hline & $\begin{array}{l}\text { Received: } 11 \text { Feb } 2017 \\
\text { Peer Review: } 11 \text { Feb } 2017 \\
\text { Revised: None }\end{array}$ & $\begin{array}{l}\text { Accepted: } 03 \text { Apr } 2017 \\
\text { Published (O): } 30 \text { Apr } 2017 \\
\text { Published (P): } 30 \text { Apr } 2017\end{array}$ \\
\hline & & \\
\hline
\end{tabular}

\section{INTRODUCTION}

Muscular variations are commonly observed during cadaveric dissection. These variations are in the form of abnormal origin or insertion, accessory slips of the muscles, anatomical variants and absence of the muscle. Apart from cadaveric dissection, some muscular variations are reported at the time of surgical and radiological procedures [1].

Most of the times such muscular variations are 
asymptomatic but some of the patients report with compression symptoms or soft tissue swellings. Modern imaging techniques help to diagnose such variations.

Muscular variations are common in the upper limb and occur as a result of changes that occur during development. The knowledge of such variations is useful for hand surgeons and radiologists. Accessory muscles in the human forearm have been described by Gantzer in 1813 [2]. Nerve entrapments are common with variations of muscles. In such cases knowledge of variant muscles is necessary prior to surgical decompression to avoid intra-operative complications. In arthritis of thumb, deformed and dysfunctional hand can be improved / transformed into functional hand for basic functional needs by tendon transfer. Accessory muscles like Flexor carpi radialis brevis, if present could be used for tendon transfers. This study was carried out with the aim of providing account of accessory muscles in the flexor compartment of the forearm with considerably larger sample size.

\section{MATERIALS AND METHODS}

Present study was carried out in the Department of Anatomy of MIMER Medical College, Talegaon Dabhade, Dr. DY Patil Medical College, Dr. D. Y. Patil Vidyapeeth Pune and BKL Walawalkar Rural Medical College, Sawarde Dist. Ratnagiri. For the present study 156 upper limbs of unknown sex were dissected, out of which 80 limbs were from right side and 76 from left side. Accessory and anatomical variant muscles in the flexor compartment of the forearm were observed and studied for its origin and insertion, size and shape and important relations.

Table 1: Percentage prevalence of accessory muscles in present study.

\begin{tabular}{|l|c|}
\hline \multicolumn{1}{|c|}{ Variations observed } & Number (\%) \\
\hline ahFPL & $56(36 \%)$ \\
ahFDP & $5(3.2 \%)$ \\
ahFDS & $2(1.2 \%)$ \\
ahFCU & - \\
Two accessory bellies & $5(3.2 \%)$ \\
Anatomical variant (FCRB) & $1(0.64 \%)$ \\
\hline
\end{tabular}

\section{OBSERVATIONS AND RESULTS}

Forearm has superficial and deep groups of muscles. Accessory heads for flexor pollicis longus (ahFPL), and for flexor digitorum profun- dus (ahFDP) are called as Gantzer's muscles. In our study accessory bellies were found for the flexor pollicis longus (FPL), flexor digitorum profundus (FDP), flexor digitorum superficialis (FDS) and double bellies. One anatomical variant, Flexor carpi radialis brevis (FCRB), which is not very common, was found in one limb. Table 1 shows percentage prevalence of accessory muscles in present study. For the sake of clarity variations are discussed separately.

Accessory head for FPL (ahFPL): Flexor pollicis longus belongs to the deep group of flexors. It originates from concave anterior surface of radius inferior to radial tuberosity and anterior oblique line of radius, and inserted into base of distal phalanx of thumb. Gantzer named accessory head of FPL as "Accessorius ad flexorem pollicis longum", hence called as Gantzer's muscle [3]. This muscle has been reported by many workers as case reports and comparatively less number of variation studies.

This variation was the most common observation in the present study and observed in 56 (36\%) of limbs.

Prevalence: On right side prevalence was 34\% (27 limbs) and 38\% (29 limbs) on left. Prevalence of ahFPL has been mentioned by Le Double as $33 \%, 55 \%$ by $\mathrm{M}$. Jones and by Wood as $75 \%$, while in one Indian study Pai MM et al. have reported it as $46.03 \%[3,4,5]$. In the present study it is $36 \%$, little higher on left side $38 \%$ than right side $34 \%$, this is accordance with the results by Le Double.

Origin: The origin of ahFPL is mainly from coronoid process or medial epicondyle via fibres of FDS. The most common singular point of origin from under the surface of FDS has been reported by M. Jones [4]. Wood has reported the origin of ahFPL from coronoid process of ulna. [3]. Origin from brachialis muscle, oblique cord, pronator teres or intermuscular flexor fascia is also reported. In the present study 54((96.5\%) limbs, ahFPL had origin from under surface of FDS, in one limb from FDP and one from brachialis muscle (Tab.2).

Insertion (Table 2): Accessory belly runs obliquely downwards and laterally and gets attached to tendon of FPL on its ulnar side. Length of tendon is variable from few millimetres to few 
inches. In 7(12.5\%) limbs, very sort belly and tendon was inserted to main tendon in upper $1 / 4^{\text {th }}$ part. In majority of the limbs $37(66 \%)$ insertion of tendon was in upper $1 / 3^{\text {rd }}$ part. In $9(16 \%)$ tendon was long and reached up to middle part of the main tendon and in one case tendon inserted at the level of flexor retinaculum (Fig.1). $\mathrm{M}$. Jones and P. H. Abrahams has reported its insertion in upper $1 / 3^{\text {rd }}$ part of the forearm in $75 \%$ of the cases, in the middle $1 \beta$ rd in $22.2 \%$ and lower $1 / 3^{\text {rd }}$ in $2.8 \%$

Table 2: Origin and insertion of ahFPL in the present Study.

\begin{tabular}{|l|c|}
\hline \multicolumn{1}{|c|}{ ahFPL (total no. 56) } & Number (\%) \\
\hline Origin & \\
Under surface of FDS & $54(96.5 \%)$ \\
FDP & $1(1.7 \%)$ \\
Brachialis & $1(1.7 \%)$ \\
\hline Insertion & \\
Upper $1 / \mathbf{4}^{\text {th }}$ of forearm & $7(12.5 \%)$ \\
Upper $1 / \mathbf{3}^{\text {th }}$ of forearm & $37(66 \%)$ \\
Middle of forearm & $9(16 \%)$ \\
Wrist & $1(1.7 \%)$ \\
\hline
\end{tabular}

Fig. 1: FPL: Flexor Pollicis Longus, FDP: Flexor Digitorum Profundus, Arrow (Yellow): Accessory Head of Flexor Pollicis Longus, Arrow (Black): Tendon of Accessory Head of Flexor Pollicis Longus, Arrow (Red): Insertion of Accessory Head of Flexor Pollicis Longus.

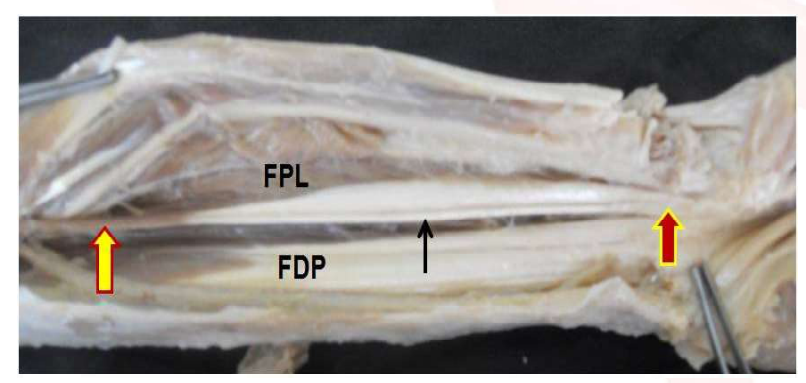

Size and length of the bellies is also variable form slender to massive and short to considerably long. Its relations are important as it is related with two nerves anterior interosseous nerve (AIN) deep to it and median nerve superficial. In our study AIN was deep to ahFPL in all cases. Al-Quattan has reported that AIN passing superficial to ahFPL [6]. M.Jones, P.H. Abrahams reported that in $8.8 \%$ of cases ahFPL had dual nerve supply by AIN and median nerve [4]. Anterior interosseous nerve is susceptible for compression as it runs on the tough interosseous membrane. Compression of nerve by soft tissue, or vascular or bony structure leads to AINS. Fractures of forearm, contusion injuries, pressure on forearm are the major causes for nerve entrapment. Accessory muscles in the forearm and tendinous arches of muscles play major role in the entrapment of AIN [7]. Manifestations of AIN syndrome depend upon type of relationship of nerve with ahFPL and syndrome may be of complete or incomplete type [8].

Modern humans are unique among hominids in having a FPL muscle separate from FDP. In extant great apes FPL is absent and tendon for thumb might be present from belly of FDP [9]. Though it is absent in great apes lesser apes like gibbons and baboons share extrinsic FPL with humans. Flexor pollicis longus stabilizes the flexed phalanx of thumb during various grips of hand like precision grip or power grip.

Electromyographic (EMG) studies has revealed more activity of FPL in power grip, indicating use of FPL in hominids with improved performance, particularly during vigorous and forceful tool using and stone tool making [10]. Accessory belly of FPL is fusiform and attached to tendon of unipennate FPL from opposite side, so direction of pull of ahFPL is opposite to FPL. This could interfere with performance or may have extra strain on FPL [11] and needs to be evaluated by EMG studies.

Accessory head for FDP (ahFDP): In the present study this variation was observed in five (3.2\%) limbs, three on right side and two on left sides. In four cases origin was from FDS and in one from medial side of coronoid process. Reported prevalence of ahFDP is $2.9 \%$ by Mangini 1960, $\& 18.6 \%$ by wood $[9,3]$. Wood has described ahFDP arising in common with FDS and tendon inserting into tendon of index finger in two cases and for the tendon of middle finger in one case.

Accessory head for FDS (ahFDS): This variation was found only in two limbs $1.2 \%$, one for right limb and other for left. In the present study origin of ahFDS was from FDP and insertion was in the slip of the muscle for middle finger.

Two accessory bellies: Prevalence observed in the present study is $3.2 \%$ (5 limbs). Vasavi R. G. et.al. in a case report have mentioned two accessory bellies, one for FPL and another for FDP with common origin from under surface of FDS [12]. Our findings in three limbs share with this study (Fig. 2). Two accessory bellies for FPL has 
been reported by Roshani Bajpe in one limb [13]. In the present study, in a left limb both the bellies were for FPL inserted together but with different origin one from under surface of FDS another from lower part of radial tuberosity. In one limb two bellies with separate origin, one for FPL and another FDS were found.

Fig. 2: FDS: Flexor Digitorum Superficialis, FPL: Flexor Pollicis Longus, FDP: Flexor Digitorum Profundus, ahFPL: Accessory Head of Flexor Pollicis Longus, ahFDP: Accessory Head of Flexor Digitorum Profundus.

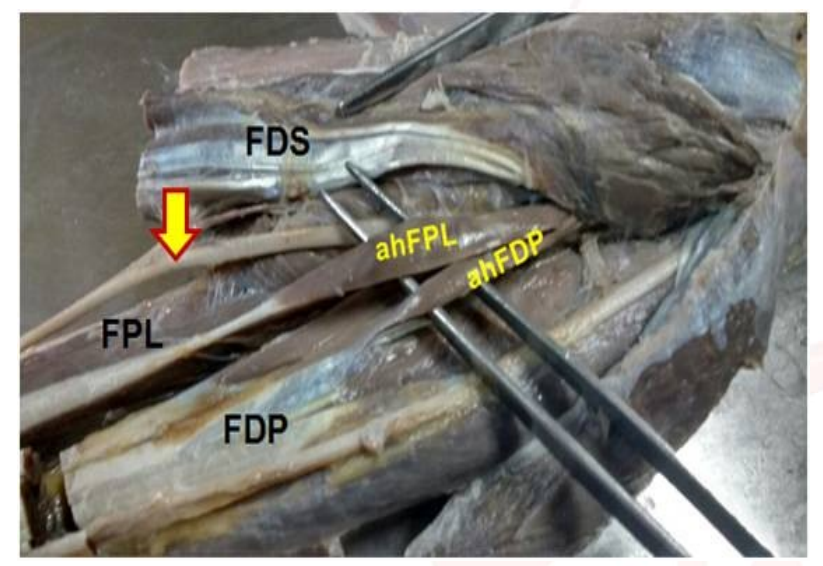

Flexor carpi radialis brevis (FCRB): This rare variation was found on left side. Its proximal attachment was aponeurotic and to the anterior oblique line of the radius, deep to insertion of pronator teres (Figure 3). After origin, medial aponeurotic part merged with fascia covering Flexor Carpi Radialis (FCR). Distally muscle belly was formed. Tendon of the muscle was very thin and distally it merged with flexor retinaculum lateral to tendon of FCR (Figure 4). At origin it was deep to the insertion of pronator teres. It was accompanied by FCR medially and brachioradialis laterally. Deep to this muscle was flexor pollicis longus (FPL). This muscle was supplied by branch from AIN.

Fig. 3: BR: Brachioradialis, PT: Pronator Teres, FCR: Flexor Carpi Radialis, FCRB: Flexor Carpi Radialis Brevis with its aponeurotic origin (Arrow).

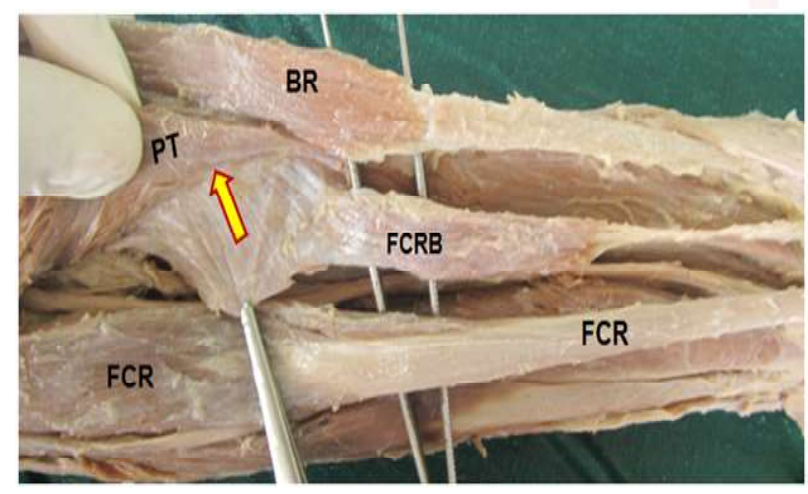

Fig. 4: BR: Brachioradialis, PT: Pronator Teres, FCR: Flexor Carpi Radialis, FCRB: Flexor Carpi Radialis Brevis with its tendon (Arrow).

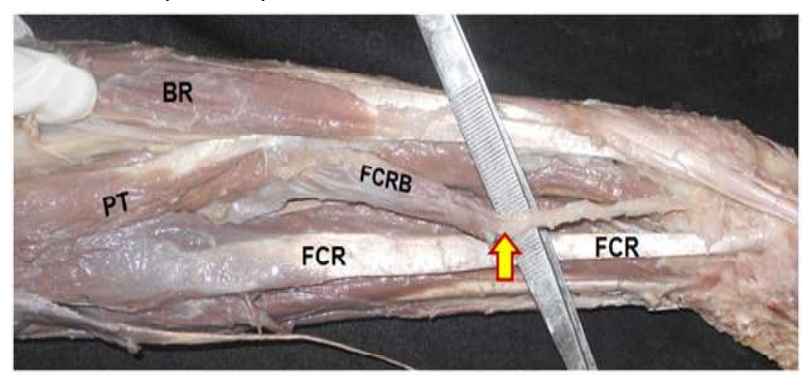

It is homologous with tibialis posterior of the inferior extremity. It was first described by Fano in 1851 and the name 'Flexor Carpi Radialis Brevis vel Profundus' was given by Wood in 1866-67 [2]. Fano himself named it as 'court radial anterieur' (short anterior radial). Most common origin is from anterior oblique line or anterior surface of the shaft of the radius. Origin from lateral and anterior surface of lower $1 /$ $3^{\text {rd }}$ of radius is reported by Alice Carleton [14]. It may take origin from ulna or anti-brachial fascia. Lower attachment or the insertion is also variable. It is most commonly inserted into carpals (mainly scaphoid, trapezium or trapezoid), metacarpals or both. Sometimes it merges with the sheath covering tendon of FCR and shares insertion with it or it may get inserted/ merged with carpal ligament or flexor retinaculum. Based on its lower attachment Fano classified it as

a) Radio-carpal, b) Radio-metacarpal

c) Radio- carpometacarpal.

It may receive additional fibres from pronator teres or pronator quadratus. Prevalence of this muscle is variable. Recently more cases are reported in cadaveric studies as well as in vivo. $5 \%$ incidence is reported by Ronald Bergman [15], while $8.7 \%$ by S.Y.M. Ho [16]. In vivo cases are usually asymptomatic, accidental findings but tenosynovitis of this muscle may present as a painful forearm swelling $[17,18]$.

In the present study, origin was from anterior oblique line of radius deep to pronator teres and lower attachment was to flexor retinaculum lateral to FCR.

First carpo-metacarpal joint (joint of thumb) is more commonly subjected for arthritis. One of the methods for the treatment of thumb arthritis is interposition arthroplasty with ligament reconstruction. In this method, tendon of FCR is 
used to fill the gap created/ formed by removal of trapezium. In some cases additional tendon is needed to improve grip and pinch strength with better prognosis, where flexor carpi ulnaris (FCU) is used [19]. In such cases if additional muscle like FCRB is available, this could be used in arthroplasty.

Fractures of the distal end of radius (Colle's fracture) are common in elderly females and younger age group. Internal fixation of the radius is one of the methods for the management of Colle's fracture. Internal fixation of radius helps to achieve anatomical reduction with improved functional out come. In a classical volar approach, plane between flexor carpi radialis and brachioradialis is used for internal fixation of lower end of radius [20]. Volar approach to distal end of radius needs knowledge of anatomical relations and possible variations. In this region radial artery and superficial branch of radial nerve are present. Presence of additional variant muscle like FCRB may cause difficulties in exposure to radius and there may be danger of injury to neurovascular structures. Edward Laugharne and Dominic Power have reported that during surgical management of Colle's fracture, exposure to distal end of radius was more difficult because of variant muscle FCRB [20]. Mantovani G reported six cases of FCRB in 172 patients, surgically managed for radial fracture fixation by volar approach [21].

Functionally this muscle is radial flexor of wrist assisting FCR. If its origin extends to ulna or medial epicondyle then it assists in pronation.

Embryological basis: Limb muscles are derived from abaxial domain that consists of parietal layer of lateral plate mesoderm in combination with somite- derived cells. Forearm flexors develop from flexor mass which divides into superficial flexor mass and deep flexor mass. From deep flexor mass flexor carpi ulnaris (FCU) develops first. Remaining portion differentiates into flexor digitorum profundus (FDP) and flexor digitorum superficialis (FDS). Flexor pollicis longus develops by septation of FDP [22]. Superficial muscles are derivatives of superficial flexor mass (flexo-pronator). Incomplete cleavage or more fragmentation of flexor mass explains presence of additional muscles. More fragmentation of flexo-pronator mass could be the embryological basis for FCRB.

\section{CONCLUSION}

Knowledge of muscular variations such as accessory muscles or variant muscles is essential for diagnosis of nerve entrapments, during imaging procedures and to avoid complications during surgeries. Such muscular variations are clinically significant in cases of nerve entrapments and additional muscles like FCRB are of major help to improve disabilities of thumb arthritis by tendon graft/ transfer.

\section{ABBREVIATIONS}

ahFPL- Accessory head for the flexor pollicis longus

ahFDP-Accessory head for the flexor digitorum profundus

ahFDS- Accessory head for the flexor digitorum superficialis

FCRB - Flexor carpi radialis brevis

AINS- Anterior interosseous nerve syndrome

FPL- Flexor pollicis longus

FDP- Flexor digitorum profundus

FDS- Flexor digitorum superficialis

EMG-Electromyographic

AIN-Anterior interosseous nerve

FCU- Flexor carpi ulnaris

\section{ACKNOWLEDGEMENTS}

We acknowledge Dr. S.P. Jog Ex-Professor and Head MIMER Medical College, Talegaon Dabhade for her timely guidance and support and Dr. Savita Gaikwad, Dr. Jasbir kaur Garcha, Mr. Ramesh Babu for their help in collection of data.

Conflicts of Interests: None

\section{REFERENCES}

[1]. Scott F.M. Duncan, Richard R.McCormack, Jr., Catherine C. Roberts. Characteristics of the Flexor Carpi Radialis Brevis Tendon on Magnetic Resonance Imaging and its Use in Basal Joint Arthroplasty. Radiol Case Rep.2006;1(1):24-6.

[2]. Le Double AF, Traite des variations du systeme musculaire de. I'homme, Schleicher Freres Paris 1987;2:141-148.

[3]. Wood J. Variations in human myology. Proceedings of the Royal Society of London 1868;16:483-525.

[4]. M. Jones, P. H. Abrahams. Incidence and morphology of accessory heads of flexor pollicis longus and flexor digitorum profundus (Gantzer's muscles).J. Anat. 1997;191:451-455. 
[5]. Pai MM, Nayak SR, Krishnamurthy A, Vadgaonkar R, Prabhu LV, Ranade AV, Janardhan JP, Rai R. The accessory heads of flexor pollicis longus and flexor digitorum profundus: Incidence and morphology. Clin Anat. 2008;21(3):252-8.

[6]. Al-Qattan MM. Gantzer's muscle. An anatomical study of the accessory head of the flexor pollicis longus muscle. J Hand Surg Br. 1996 Apr;21(2):26970.

[7]. Gunnal S.A., Siddiqui A.U., Daimi S.R., Farooqui M.S., Wabale R.N. A Study on the Accessory Head of the Flexor Pollicis Longus Muscle (Gantzer's Muscle). Journal of Clinical and Diagnostic Research. 2013;7(3):418-421.

[8]. Bhagath K P, Vasavi R G, Thejodhar P, M. S. Rao, Mamatha T., Venkata Ramana V \& Nayak. S. R. Accessory Head of Flexor Pollicis Longus Muscle and its Significance in Anterior Interosseous Nerve Syndrome: Case Report and Review. Int. J. Morphol. 2007;25(4):911-914.

[9]. Mangini U. Flexor Pollicis Longus Muscle Its Morphology and Clinical significance. journal of Bone and Joint Surgery 1960;42A:467- 470.

[10]. Mark W. Hamrick, Steven E.Churchill, Daniel Schmitt \& William L. Hylander. EMG of the human flexor pollicis longus muscle: implications for the evolution of hominid tool use. Journal of Human Evolution 1998;34:123-136.

[11]. S. Sundaram Mani, Vishnumaya G, Madan Kumar SJ. Accessory head of flexor pollicis longus and its significance in anterior interosseous nerve neuropathies and precision handling. International Journal of Anatomical Variations 2010;3:46-48.

[12]. Vasavi RG, Bhagat Kumar P, Venkata Ramana V, Thejodhar P. Rare Origin of Two Accessory Bellies from the Undersurface of the Flexor Digitorum Superficialis Muscle. European Journal of General Medicine, 2009;6(1):57-59.
[13]. Roshni B, Tarkeshwari R, Shubha R. Gantzer Muscles; a study on 50 cadaveric upper limbs. National Journal of clinical Anatomy. 2015;4(4):179-185.

[14]. Carleton A. Flexor carpi radialis brevis vel profundus. J Anat 1935;69(Pt 2):292-293.

[15]. Bergman RA, Afifi AK, Miyauchi R. Illustrated Encyclopedia of Human AnatomicalVariations. http:// www.anatomyatlases.org/AnatomicVariants/ MuscularSystem/Text/F/05Flexor.shtml. (Accessed January 2015)

[16]. Ho SYM, Yeo CJ. The flexor carpi radialis brevis muscle- an anomaly in forearm musculature: a review article. Hand surg. 2011;16(3):245-249.

[17]. Peers SC, Kaplan FT. Flexor carpi radialis brevis muscle presenting as a painful forearm mass: case report. J Hand Surg Am. 2008; 33(10): 1878-81.

[18]. Kosiyatrakul A, Luenam S, Prachaporn S. Symptomatic flexor carpi radialis brevis: case report. J Hand Surg Am. 2010;35(4):633-5.

[19]. Kristofer S, Asif I, Joseph J.Thoder. CMC arthroplasty of thumb: a review. Hand 2007;2(4):232-239.

[20]. Edward L, Domnic P. Surgical exposure of the distal radius in patients with a flexor carpi radialis brevis muscle anomaly. http://jscr.co.uk (accessed May 2013).

[21]. Mantovani G, Lino W Jr, Fukushima WY, Cho AB, Aita MA. Anomalous presentation of flexor carpi radialis brevis: a report of six cases. J Hand Surg Eur Vol. 2010; 35(3): 234-5.

[22]. Lewis WH. The development of the muscular system in Mannual of human Embryology by Franz Keibel \& Franklin P. Mall. Philadelphia: J.B. Lippincot. 1910; 455-522.

How to cite this article:
Pushpa Burute, P. Vatsalaswamy. ACCESSORY HEADS OF
FOREARM FLEXORS AND FLEXOR CARPI RADIALIS BREVIS: A
CADAVERIC STUDY WITH CLINICAL SIGNIFICANCE. Int J Anat Res
2017;5(2.1):3698-3703. DOI: $10.16965 /$ ijar.2017.145 